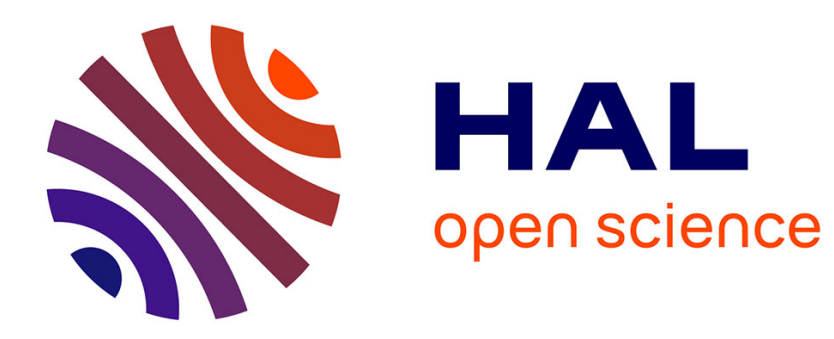

\title{
Exploration and Project Management
}

Sylvain Lenfle

\section{- To cite this version:}

Sylvain Lenfle. Exploration and Project Management. International Journal of Project Management, 2008, 25 (6), pp.469-478. hal-00404168

\section{HAL Id: hal-00404168 \\ https://hal.science/hal-00404168}

Submitted on 22 Jul 2009

HAL is a multi-disciplinary open access archive for the deposit and dissemination of scientific research documents, whether they are published or not. The documents may come from teaching and research institutions in France or abroad, or from public or private research centers.
L'archive ouverte pluridisciplinaire $\mathbf{H A L}$, est destinée au dépôt et à la diffusion de documents scientifiques de niveau recherche, publiés ou non, émanant des établissements d'enseignement et de recherche français ou étrangers, des laboratoires publics ou privés. 


\title{
Exploration and project management
}

\author{
Sylvain Lenfle \\ University of Cergy-Pontoise \\ Management Research Centre - Ecole Polytechnique, Paris, France
}

\author{
Contact information : \\ Centre de Recherche en Gestion \\ 1 , rue Descartes \\ 75005 Paris \\ Mail : $\underline{\text { slenfle@hotmail.com }}$
}
Published in the International Journal of Project Management, Vol. 6, n5, p. 469-478, July.

\section{Abstract}

Project management in academic studies tends to be regarded as an adequate solution to the problems raised by innovation. This paper sets out to question this tendency to equate projects and innovation which, in our view, can lead to the improper use of projects to manage innovation. We argue that, in line with the work on project classification, a distinction should be made between the various types of design situations to which different types of projects are suited. Qualitative research on automotive telematics allows us to identify the management methods suited to the most innovative projects, i.e. exploration projects for which neither technologies nor customer requirements are known at the start of the project. We will show how these situations shake up traditional project management models and will propose five management principles adapted to this new situation. 


\section{Introduction}

The strategic role of new product development and innovation [57, 67, 30, 10] makes design performance a central concern for managers. Project management therefore appears to be an adequate solution to the integration problems raised by these activities. Adler [3], for example, sees the project as the main way to implement innovations. Work such as that by Clark \& Fujimoto [18] has thus helped make heavyweight project management a dominant organizational model. This is a major characteristic of American managerial literature. The leading US manuals [for example, Burgelman et al. 12] cover in detail the way in which the innovation process is carried out, technology analysis tools, industry development, etc., but offer little insight into the organization appropriate to innovation. This topic is approached either via the resourcebased model [30], from the perspective of functional policies or, when the question of integration is raised, via project management models. The article by Clark \& Wheelwright [19] on heavyweight project management is therefore a key point of reference.

In this article, we wish to question this tendency to equate projects and innovation. This tendency can, in fact, appear surprising inasmuch as Clark \& Fujimoto [18] indicate that their research does not take into account the question of advanced engineering or basic research (p. 26). We therefore believe that it can lead to improper use of the project format to manage innovation. We argue that, in line with work on project classification $[67,60,5]$, a distinction should be drawn between the various design situations to which different types of projects are suited.

Qualitative research [23] conducted at a European automobile manufacturer will allow us to identify the management methods suited to the most innovative projects, i.e. those for which neither technologies nor customer requirements are known at the start of the project (referred to by Atkinson et al., [4] as "soft" projects). Following James March's definition, we will call them exploration projects. We will show how these situations disrupt traditional project management models and we will propose management principles adapted to this situation. 


\section{Projects and innovation: an analysis of the literature}

\subsection{Project and innovation management : the missing link}

The links between studies devoted to project management and innovation management are complex and marked by a relative lack of communication between the two fields.

On one hand, there is a tendency in project management literature to equate project and innovative organization. Thus Cleland \& Ireland [20] recommend project management "to any ad hoc undertaking" (p. 69) and state that "the justification for project management arises from the need for new or improved products, services or organizational processes" (ibid.). They then propose criteria for assessing the need to resort to a project and recommend its use for innovation situations. However, their reasoning stops there while the "newness" of the situation relates, as we will see, to very diverse situations. Furthermore it is striking to note the gap between a definition of projects that stresses novelty, and mainstream literature which propose an instrumental view of Project Management (typically the PMI Body of Knowledge, [22]). While criticized in recent years (e.g. the special issue of this journal on Rethinking Project Management, 2006, vol. $24 \mathrm{n}^{\circ} 8$ ) this "rational” view of project management as the accomplishment of a clearly defined goal in a specified period of time, within budget and quality requirements, remains dominant in most textbooks and discourses on project management. But we can wonder if this is adapted to innovation management. Actually innovation is first and foremost characterized by divergence [66] and unforeseeable uncertainties which render the rational approach irrelevant [48].

On the other hand studies on innovation management maintain complex relations with those devoted to projects. Organization by projects is rarely mentioned, even if this mode of management is frequently underlying. Thus, the project format is typical of “organic” operations, although Burns \& Stalker [13] make no reference to it. In the same vein, Van de Ven et al. [66] never mention it, although the situations studied often correspond to a project-based organization. Moreover, the principles proposed by Van de Ven in his 1986 paper (Self-organizing autonomous units, redundant functions, requisite variety, temporal linkage, [65]) clearly correspond to 
project management. This format therefore seems, at first sight, to be the organizational model suited to innovation management (see also [54]).

This link between projects and innovation is also established by research on the key success factors of innovation. Maidique \& Zirger [50] play here a pivotal role. Specifically, they show that managerial excellence, defined explicitly as effective project management, is the main reason for successful innovations [50, pp. 879-880]. But, again, the analysis of project management practices stops here, and they quote Nonaka \& Takeuchi [57] as examples of best practices in the management of innovative projects.

\subsection{The emergence of a dominant model}

The link between projects and innovation is thus brought to the fore by the study of Japanese firms which, during the 1980's, were increasingly successful on the US and European markets. Works by Imaï, Nonaka \& Takeuchi [35], Nonaka \& Takeuchi [57], Clark, Chew \& Fujimoto [17] and Clark \& Fujimoto [18] enabled us to formalize a model of project management, referred here to as the Heavyweight Model, that would be considered as a panacea to manage new product development in mature industries.

In our view, Product Development Performance (1991) constitutes a landmark contribution to the literature on product design and project management. Clark and Fujimoto started with performance data that showed the superiority of Japanese firms. They went on to present a detailed comparative analysis of product development practices at automotive manufacturers around the world. Their contribution is twofold.

Conceptually, the authors departed from the dominant Project Management literature which, as noted by Morris [55], focused excessively on project execution and the associated management techniques for planning, scheduling, cost control, etc. Instead, they drew on the literature on organization theory and R\&D Management (see chapter 2 in [18], especially the notes p. 32-33) and they regarded new product development as a set of information processing and problem solving activities [see 8 \& 37 for an analysis of the consequences of this approach]. The aim of the overall process was to ensure the product's integrity, i.e. its intrinsic qualities and its ability to meet the customer's expectations. For a complex product like an automobile, the greatest management challenge was to establish organizational structures and practices that ensured adequate integration of diverse skills and knowledge, including the customers' knowledge about what it was like to use the product. This illustrates the structural 
convergence between the project mode of organizing and the challenge raised by innovation. Indeed research on innovation management underlines:

- The crucial role of the integration of the expertise necessary to the success of innovation [38, 34],

- The need for flexibility in order to adapt to the evolution of the environment and the resulting feedback between the different phases of the process [13, 36, 65].

This helps us to understand the attraction of projects in managing innovations even if, as we will see, this a priori convergence may be dangerous.

On the operational side, Product Development Performance brought into focus three important new management ideas which, interestingly, emphasize the importance of organizational factors in project success: (1) heavyweight project managers; (2) overlapping problem-solving cycles (also called concurrent engineering); and (3) the integration of customers and suppliers into product development activities (see [44] for a summary).

\subsection{Toward a contingency theory of project management}

The work from Clark \& Fujimoto seems very important because it exert a strong influence over the project management practices of European and US firms [52, 25, 27]. It thus constitutes a model of "best practices" which rapidly became synonymous with efficiency in project and innovation management. This can, in fact, appear surprising inasmuch as Clark \& Fujimoto [18] indicate that their research does not take into account the question of advanced engineering or basic research (p. 26). Moreover in another book, Wheelwright \& Clark [67] emphasizes the need to distinguish between different types of project and to adapt management methods and organization accordingly. This has been subsequently elaborated on by Shenhar \& Dvir [58-61] who proposed a four dimension typology of projects based on novelty, technology, complexity and pace. Shenhar \& Dvir research [summarized in 59] is particularly rich and interesting since it bridges the gap between PM and Innovation management literature by making extensive use of the latter. We believe however that much remains to be done to further elaborate the model proposed by Shenhar \& Dvir. Specifically they presuppose that there is always a defined objective, even potentially "new to the world", at the beginning of the project (see their definition of breakthrough projects in [59], p. 67). But this is not always the case. 
Indeed "innovation” refers to a wide variety of situations. At the most general level, following the classical Schumpeterian definition, innovation refers to the introduction of something new (goods, services, production process, etc.) on the market. However, one of the contributions of innovation management literature has been to develop this definition by identifying different types of innovation. For example, Abernathy \& Clark [1] proposed to classify innovations according to their impact on a firm's "technical” and "market" capabilities, laying the foundations for the famous competence-enhancing vs. competence-destroying innovations [63]. In this perspective the most problematic situations are those in which neither the technology, nor the customer requirements are known at the beginning of the process.

Applying this distinction to project management allows us to define our research question. In this perspective, “development” refers to a situation where the technical and market knowledge associated with the project are well-known. Most of the literature on new product development deals with this case where the teams exploit the firm's competencies. On the other hand, "exploration" refers to a situation where the technology and the market have to be explored. Both are innovations but in the latter case, the objective itself is, as we will see, unknown (or at least partially non-definable). Thus the project enters an exploration process [51] first and foremost characterized by experimentation and uncertainty. As we will see, the result of the project is then no longer simply a product. We therefore agree with contemporary thinking on "innovative design” defined as a two-fold process of exploration of knowledge and concepts which then give rise to developments or research [40, 41, 46, see also 34 for an introduction on the $\mathrm{C} / \mathrm{K}$ theory].

The central issue is therefore whether the project format is suited to the management of exploration. Research conducted at a European automobile manufacturer on telematic services $[43,46]$ shows, in fact, that exploration seriously undermines the development model which, as we have shown, is dominant in the literature. This type of design situation shows five characteristics that are problematic for project management. Before analyzing these characteristics, we will present our methodology. 


\section{Research Design and data}

To study these questions, in 2001 we made contact with a leading European car manufacturers, here identified as Telcar for reasons of confidentiality. Following a presentation of our previous research on managing innovative projects $[41,45]$ Telcar gave us permission to study the case of Telematic Services. Before describing our methodology for data collection in detail, we shall start by providing an overview of these services.

\subsection{Research Site}

New Information and Communication Technologies (NICTs) have for several years constituted a very fertile field for innovation with the proliferation of initiatives relating to telematics services for automobiles, the "communicating car". These terms refer to the motorist's ability to access, from the vehicle itself, a certain number of services, which are customarily grouped into four areas: 1) Emergency and breakdown services, 2) Navigational aids, 3) Communication services , 4) Entertainment.

The design and exploitation of such services involves various actors in complex cooperation processes. Service providers generate the information needed for the service (e.g. traffic information) and operate the service platform (e.g. the emergency call centre); telecom operators develop and maintain the communication systems that connect the car to the service operators; car equipment suppliers develop the onboard systems needed for the service (e.g. integrated radio, GPS and GSM equipment); car manufacturers specify, integrate and market the new services and onboard equipment.

The first commercially available application, Onstar, was launched by GM in 1996, and other manufacturers quickly followed, without the same success. The ambitious predictions made in 2003 were never realized and GM - which claims to have 4 million subscribers $^{1}-$ is the only manufacturer that has achieved a certain degree of success as far as concrete results are concerned; at the other end of the scale, European manufacturers are experiencing great difficulties [46]. And looking beyond the distribution of these innovations, the strategic and financial benefits of injecting

\footnotetext{
${ }^{1}$ Source : www.OnStar.com, Press Room, accessed June 25, 2007. See also [16].
} 
massive investment into this field of innovation remain very uncertain for manufacturers.

\subsection{Data collection and analysis}

Data collection was performed over a three-year period. This enabled us to take part in the real-time design process and in the marketing of the first telematic service (emergency and breakdown call launched in February 2003: see [47]). Consequently, we were able to follow and analyze the whole design process, and then observe its results. To do this, we received support from the Project Manager as well as from its main sponsors. As a result, we had virtually unlimited access in the field. The duration and frequency of the interaction with the design team enabled us to follow the development of the design process accurately and gain access to data sources usually closed to outsiders. We relied on three typical sources of data for qualitative research: semi-structured interviews, participation in relevant meetings and company documents.

Following the paradigm of grounded research [23, 53, 69] our analysis was founded on detailed field notes - interview notes, transcripts of project meetings, company documents - compiled into detailed case studies for each phase of the design process. This process was iterative as the cases were frequently updated after follow-up discussions with respondents. Each case study report was re-read by key information providers and discussed during bi-annual research meetings involving the project manager and members of the project steering committee. These meetings simultaneously enabled the results presented to be confirmed and the directions taken by the research to be discussed.

\section{The impact of exploration on projects: the destabilization of the development model}

This research allows us to analyze the gap between development and exploration situations, leading onto a study of the adaptation of project management to these exploration situations. More precisely we have identified five characteristics of “exploration projects” that destabilize the “development” model. 


\subsection{Emerging, strategically ambiguous projects (C1)}

In development projects, the strategy is formulated prior to the project's implementation. In exploration projects, such prior definition of a strategy is difficult, simply because there is no shared understanding of the phenomena and causalities needed to formulate a strategy. What are, for example, the uses of "hydroforming" [41]? What is a telematic service [46]? How does one define an "autonomous flying vehicle" [32]? Here it is clear that it is impossible to first define the strategy and then begin the project. On the contrary, the project will make it possible to gradually define the strategy [11].

This characteristic can be problematical, since it can be a source of confusion and misunderstanding over the objectives pursued by the various participants in the project. For example, two different strategic outlooks underlie current initiatives in the area of telematics services:

- The first continues the dominant automotive strategies [e.g. 18, 52]: adding features via innovative onboard equipment able to support services. In this perspective telematics follows airbags, ABS, the keyless car etc.

- In the second strategic vision, the goal is to reinvent Customer Relationship Management (CRM). Winer [68] has shown the difficulty of establishing a lasting customer relationship in this industry. In this context, Telematics becomes a means to create a direct relationship with customers.

In principle these two strategic outlooks appear very similar and entirely compatible: the car manufacturer can launch innovative equipment that simultaneously supports new services used to improve his CRM strategy. But in fact, the two strategies imply different priorities for the project teams:

- Time-to-market is therefore key in the first instance, while in the second, redefining a CRM strategy involves more time.

- Similarly, there are differing business models associated with the two strategies: the first strategy is based on sales of equipment; in the second, profits are more indirect, but also more lasting (i.e. improved customer loyalty).

The example of the Telematic project shows that the obstacles and changes lead the team to study different scenarios which help to progressively define the strategic goals pursued. 


\subsection{A proactive approach (C2)}

The second difficulty lies in the fact that there is no explicit demand on the part of customers, and therefore no clearly identified market. This raises two problems. The first one refers to the legitimacy of the project in the organization. As shown for example by Dougherty \& Hardy [21] or Christensen [15] exploration projects frequently suffer from their inability to secure the resources required because of their illegitimacy regarding the dominant logic of the firm. Secondly this raise the question of the target audience (Who are the customers? What do they want?)

The problems currently being encountered in Telematics can be summed up in two major difficulties [46]:

- Defining the content of telematics service - The list of possible services is very large (from assistance to traffic information and e-mail services) and their design complex, and Telcar cannot rely on prior experiences.

- Assigning a value to the innovative service - This is primarily a problem that stems from the fact that customers "do not know what they are buying” and, with the exception of a few "killer apps", are not willing to pay extra for it. But the problem also stems from the fact that the business models for these services are new for the automobile industry: subscriptions, pay-per use, the involvement of third-party financing and so on.

\subsection{The difficulty of specifying the result of the projects (C3)}

This absence of clearly identified customers challenge one of the basics of project management: the existence of a clearly defined objective. Moreover, divergence can be conceived as a structural characteristic of innovation [66]. Therefore the result of the project becomes difficult to define. Specifically, the goal cannot only be to develop a product whose characteristics are relatively clearly defined beforehand, as in a traditional development project. Launching a service is not an end in itself for this kind of project. Rather, the goal should be to develop concepts and to create knowledge that can be quickly applied to the design of other applications. Without this perspective, the investments required would not be profitable. As a result the total sales figure gives only a very incomplete picture of the project's achievements. This raises an important question since it is well known that goal clarity is a powerful motor for energizing development projects. However, management of exploration projects cannot count on 
this mechanism due to the relatively abstract, uncertain and diffuse character of the results and the stakes involved.

Nevertheless recent advances in the theory of design help us clarify the "results" of this kind of project. With reference to Le Masson, Weil \& Hatchuel [40], we can identify four different results for this project:

1. Concepts that, after development, become commercial products

2. Concepts that have been explored but adjourned due to lack of time or resources

3. New knowledge that has been used during the exploration and can be re-used on other products (e.g. components, technical solutions, new uses, and so on)

4. New knowledge that has not been used during the exploration but can be useful for other products.

More than an absence of clearly defined objectives, we should therefore talk about a new type of objective. This will take into account that, given the divergent nature of the exploration process, the team cannot manage only the (apparently) most promising product. Instead they lay the foundations for "lineages” of products (see below).

\subsection{Exploration of new knowledge (C4)}

Exploration projects make use of a technical innovation, a new practice, a new business model, etc. which, by definition, are not stabilized. As a result, the team will have to explore and develop new knowledge, which adds great uncertainty to the process. This high level of uncertainty has two consequences.

First, there is a much lower probability that such innovation will ultimately succeed. This explains the culture of caution that has taken root in this situation. Given the lower likelihood of success, firms hesitate to invest in extensive research. This makes it difficult to implement the principle of anticipation so important in modern project management. This has all too familiar consequences, such as endless projects that do not immediately use many resources... but do not produce any result either.

Second, unlike development projects where the result is the attainment of an objective, the knowledge management dimension is therefore ever-present and entails exploring an innovation field as quickly and as effectively as possible. In this context, the project is a probe and learn process [49] in which the marketing of a product/service must be viewed as a way to increase knowledge of the initially unknown innovation 
field. The effectiveness of management is therefore equivalent to the effectiveness of a learning/knowledge creation process.

This uncertainty radically changes the unfolding of the design process. Indeed, project management for products has been structured in such a way as to uncouple the elimination of major uncertainties (i.e. the role of front-end activities) from development. This uncoupling is particularly problematical in the case of telematics. On the contrary, product development and the establishment of an upstream knowledge base cannot be separated. When dealing with innovative applications learning from the market [40] is fundamental in the knowledge creation process. Moreover experimentation is unavoidable and it is necessary to make the best of such failures by capitalizing on the lessons they provide.

\subsection{A specific temporality: hidden urgency and a multiplicity of time horizons (C5)}

The development of a new product within the framework of development projects is a process driven by milestones and limited by commercial necessity. In the 1990's the implementation of heavyweight project management played a crucial role to make timeto-market the central rhythm of the firm and its suppliers [27, 52]. Urgency is built-in and is a powerful tool for motivating those involved [9, 29]. For an exploration project, the situation is characterized by the concept of "hidden urgency". The innovation developed must be integrated into the development projects. However, the window of opportunity for achieving this is very narrow (one year during advanced development in the auto case, see [41]). Moreover, the team cannot limit its horizon to a single project. The fact that the various processes overlap therefore makes the deadlines difficult to discern. One will need to decide which project to focus on in the short term in order to introduce the first version of the products/services developed, while at the same time being mindful of the other aspects that need to be explored, an exploration that relates to subsequent projects and/or research initiatives.

\section{Managing exploration projects. The Telematic Platform as a prototype organization.}

What kind of organization would be capable of driving the exploration of such an innovative field? We can wonder if the Heavyweight Model is suited to a situation 
where it is no longer possible to specify in advance either the objectives to be attained or the course the project should take. Some recent research suggests guidelines for more appropriate tools.

- The "lineages" concept [14, 39, 40] emphasizes the dynamic structuring of product portfolio and knowledge domains over several generations of innovations based on the same "guiding concept" (e.g. telematics) but leave wide open the question of how these should be transformed into organizational and inter-firm cooperation tools.

- $\quad$ The “experiential model” formalized by Eisenhardt \& Tabrizi [21], based on the analysis of product development practices in the computer industry, underlines the role of intensive experimentation, rapid iterations, frequent milestones and powerful project leaders.

- “Innovative project management” was defined and tested in our previous research [41] to fill this gap. We formalized generic principles to manage these highly risky projects (ibid.). The Telcar Research, gives us the opportunity to test the relevance of these generic principles on what we now call "exploration" projects, a more relevant designation than "innovative”. We used this principle to analyse the organization set up by Telcar to manage its Telematics strategy.

In this part, we shall detail the results of this analysis, which focuses on one specific case, the telematics platform (TP). After presenting this organization, we will show that such exploration projects imply the development of specific management principles.

\subsection{The Telematic Platform}

Between 1998 and 2004, TelCar decided to set up a dedicated structure to organize the exploration, development and marketing of telematics services. The TP brought together, in the same location, a team of approximately twenty people representing different departments of the firm (marketing, IT, electronics, purchasing, product line management, services etc.). The TP has its own budget and operates under a single manager. This platform has a multi-faceted mission:

- it is charged with maintaining a technology watch over Telematics,

- it is responsible for defining specifications for future telematics hardware and services, anticipating problems concerning the building of equipment into vehicles, and identifying suppliers. 
- Finally, it must coordinate initial implementation of the first services.

In the following sections, we describe and analyse the running of the TP in the light of our theoretical framework. We have identified five principles that summarize the functioning of the TP and provide the basis of a project management model adapted to exploration. By doing so we hope to contribute to the emerging research field that links project and innovation management $[48,59]$.

\subsection{Management principles}

\subsubsection{Set up a dedicated organization}

The first difficulty faced by exploration projects is that of legitimacy. Given their nature, one of the major risks is to view them as a galaxy of studies conducted independently by various entities of the organization (business lines, projects, hierarchies) and/or of its partners, and not to regard them as a coherent unit with significant implications. Our first principle therefore affirms the need to set up a specific entity to manage the exploration. Formalization of an exploration project therefore results in an indivisible and coherent group of studies that concern a technique and its applications in order to gradually create overall competence in the field (uses, technical solution, partners, etc.). The difficulty then is to manage this portfolio, in which each study is carried out not only for its own sake but also for its contribution to the whole [48, 64-67].

The setting up of the TP conforms to this vision. The existence of this organization within TelCar provided the conditions for an innovative and integrated exploration in a field that essentially cuts across all boundaries - those of projects, skills, products, time constraints, and functional departments. However, at the same time as it plays out its commando role in an emerging field, this type of organization must work with existing entities, which will subsequently use and build upon what has been learned. Therefore the relationships between the exploratory unit and the organization are more complex than in Tushman \& Anderson's ambidextrous model [see also 6]. This leads us to study the various means of cooperation with other parts of the organization (technical departments, commercial structures etc.)

In the TP's case, there was an "outer circle" made up of representatives of technical departments and product lines. Members of this group were heavily involved 
in the subject while remaining attached to their original departments: they were often at the platform and participated in the "Telematic plenary", the monthly meeting organized by the TP manager to monitor the development of the project. Also included were management structures set up by the manufacturer to handle all questions connected with telematics. The members of these steering committees are usually from a more senior level in the hierarchy. The members of the "outer circle" have a dual role, which is essential since they constitute a key link in the "attachment" of the platform to the company. On the one hand, they are the representatives of the product lines and the functional departments within the platform. They complement the skills of the TP and help to clarify the policies and constraints that must be taken into account for its actions to be acceptable to the rest of the company. On the other hand, they are the representatives and channels of communication from the platform to the technical departments and product lines, and thus participate in disseminating the TP's activities within their own spheres.

While it clearly illustrates the first principle of a unifying organizational identity focused on a single concept, our analysis of the TP also reveals how difficult it is to preserve a balance between focusing on the emerging concept and maintaining cooperation among the various elements present. Our research in fact showed that:

- the TP almost ignores certain strands initiated prior to its creation;

- it was incomplete since the fields of services and sales were underrepresented compared with technical skills [47].

\subsubsection{The central role of experimentation and concurrent exploration}

The uncertainty inherent in exploration projects constitutes the second difficulty faced by the team. The traditional methods of project management are in part ineffective: no schedule, difficult task breakdown, constantly changing objectives, etc. This then raises two questions:

- What to do in this type of situation where everything is uncertain and where it is difficult, and even impossible, to anticipate problems based on past experience?

- Where should you begin? Is it necessary to explore phenomena and functionalities separately or at the same time? 
On the first point, studies on innovation and design management [9, 24, 40, 41, $48,49,62,66]$ underscore the need for action in the case of unforeseeable uncertainties, which will allow problems and solutions to be discovered. Our second principle therefore emphasizes the central role of tests (prototypes, testing, customer trials, etc.) in the management process.

Sketching out a plan of action must therefore be seen as a temporary grid over the field to be explored, allowing the learning process to begin. In this context, the design of the experiments that will prove or disprove the initial hypotheses occupies a crucial place in the management of the project. This is furthermore a key coordination element, inasmuch as no other timescale is applicable, unlike with development projects. In addition, it is a way of creating knowledge (and surprises!) that could radically change the direction of the investigation, compared to traditional development where the main purpose of testing is to confirm the validity of the solutions. The intensity of experimentation will depend on the ability of the team to generate, carry out, and learn from a continuous flow of tests $[33,62,66]$. And, indeed, the history of the TP is littered with such experiments, which, while using relatively modest means, enable testing of the projected services (prototypes on test rigs, experimentation using simplified versions of the services to be provided based on temporary agreements with various partners etc.). Loch et al. [48] have remarkably demonstrated that the difficulty here is to manage different learning strategies according to the characteristics of the situation.

The second point relates to the way in which these projects are carried out. In an extremely dynamic context, separating technical and market explorations increases the risk that an answer that is relevant at a given time is no longer relevant when the other dimensions of the problem have been resolved; consequently, the project is constantly drifting. The third principle therefore emphasizes the need for concurrent exploration [28] which must concern both concepts and knowledge. In accordance with this principle, an investigation strategy where all the studies are scheduled to run in parallel would be of much greater value than an investigation where they are scheduled sequentially. This corresponds to the idea of concurrent engineering; however, the objective is not so much time-to-market than the increased likelihood of success.

That is why the TP's mission covers everything from exploring the field to launching new services. It is in fact now well established that the validation of the first 
ideas to be developed plays an essential role in the design of innovative solutions [40, 41]. In any case, the role of the platform will evolve from phase to phase:

- The platform assumes the leadership role in the initial stages, which consist of:

- Exploring the field "defined" by the guiding concept of a "telematics service" (What services are possible? What technical solutions? Etc.);

- Screening which of these strands fit in best with the company's overall strategy. Here, the TP prepare and organize the decision-making process;

- Preparing the solution (once the concepts have been defined), by designing "halfway solutions" [44] that correspond to potential applications and have been through a validation process proving them suitable to be put forward as a credible proposal to the development project teams.

- The leadership role then passes to the traditional development projects for the final development stage, although the platform continues to monitor the implementation in order to 1) learn about implementation problems, 2) prepare future services.

The TP case demonstrates that a major difficulty here is to strike a balance between these two roles. This is typical of exploration projects which are in between research and development [see 40]. It may swing either of two ways:

- The first is a shift towards pure "research". In this case, the platform comes to be seen as a technology-watch tool, relatively isolated from the development stage. However contact with the practical side is crucial for the improvement of successive generations of applications. The platform's own experience has shown how difficult it is to attract technical people if the solutions that have been developed are not sufficiently "mature".

- Conversely, the project can veer towards the development side by taking over the whole process instead of leaving this to the traditional development projects. This problem was clearly observed on the TP, which, having noticed how technical uncertainties had plagued the vehicle project teams, took over the development of onboard hardware intended to handle future telematics services. The extent and difficulty of this development task rapidly shifted the centre of gravity of the TP's activities from a "federating pre-project phase" position in the field of telematics to the position of developing an individual product. 


\subsubsection{The dual nature of performance \& goal reformulation.}

The last difficulty relates to the management of this type of project, given that it is not possible to organize the convergence toward a pre-defined objective. One must therefore assume that each test associates a knowledge production process with a revenue creation process. Our fourth principle states that the management process must take into account these two different dimensions of performance: the value of the products and accumulated knowledge. This two-tiered dimension of project performance, very present in Clark's work [34], is now widely recognized (e.g. the "preparation for the future" dimension of project success in Shenhar \& Dvir [59, p. 2021]). However, it is still treated as a by-product of development. Use of this knowledge is a matter that is often left to the project's audit team [67, chap. 11]. Shenhar \& Dvir thus explains that "during project execution, the project efficiency [meeting schedule, budget...] is critical” [59, p. 29-30] the other dimensions being important only "after the project is complete". We believe, however, that this issue is at the heart of exploration project management, while the project is being carried out. It is one of the advantages of defining the project as a reference unit, where the team is explicitly responsible for this knowledge management among the various experiments and time scales it manages. It will then facilitate the creation of "learning rents" and "lineages" of products [40].

A management tool must therefore take these two aspects of performance into account (see rows and columns of Fig. 1). A study can therefore progress to the marketing stage without providing any new knowledge apart from the fact that there is an immediate market for the product in question. Conversely, another study might not go on to produce any revenue but may nonetheless generate crucial knowledge for understanding the technique or for defining its potential field of application. This kind of management is essential in emerging technology, where the risk of failure is very high [48]. The way the TP is defined accords with this philosophy of integrating a diversity of experiments in the exploration strategy. 
Figure 1: The dual nature of the performance of studies in the portfolio of an exploration project

\begin{tabular}{|c|c|c|c|c|c|}
\hline Studies & Customer's sector & $\begin{array}{c}\text { Service } \\
\text { definition }\end{array}$ & $\begin{array}{c}\text { Technical } \\
\text { options }\end{array}$ & Etc. & Outcome \\
\hline Study 1 & & & & & \multirow{4}{*}{$\begin{array}{c}\text { Result of } \\
\text { studies }\end{array}$} \\
\hline Study 2 & I & & & & \\
\hline$\cdots$ & $\theta$ & & & & \\
\hline Study n & 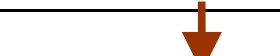 & & & & \\
\hline \begin{tabular}{|l} 
Outcome \\
\end{tabular} & \multicolumn{4}{|c|}{ at can be used elsewhere } & \\
\hline
\end{tabular}

Similarly, the management tools used must allow a reformulation of the objectives along the way (fifth principle). Projects will then be very heuristic, in which one can explore the space of potential targets and answers simultaneously, in search of satisfactory concept/knowledge combinations. The focus here is on gradually structuring the field. Performance is therefore judged according to the increasing return of the iterations [41, 45]. To start with, investigations are guided by a set of requirements that may be the evaluation of a specific technology or, on the other hand, the fulfilment of a potential customer's need. The process of seeking an answer will generate knowledge that may well call into question the relevance of the original question. The knowledge accumulated at time $\mathrm{T}$ makes it possible to better define the objectives and constraints for period $\mathrm{T}+1$ : the technical areas to be explored are clarified, certain functionalities are excluded while others emerge, the right partners are identified, and so on. Gradually, therefore, the investigations converge, or stop if the technique proves to be less useful than was previously thought.

An illustration of this situation is provided by the history of telematics within TelCar. The strategy of the company in this area became progressively clearer between the two underlying visions that we identified in the first part. Thus, following notably the dot-com bubble crash, Telcar has progressively abandoned "infotainment services" to re-focus on "automotive telematics" (emergency and breakdown calls, traffic information, etc.)

\section{Exploitation, exploration and project management}

Our analysis shows that the a priori convergence between projects and innovation can be misleading. Following the growing body of research on the contingency theory 
of project management [59, 67], we emphasize the need to distinguish different situations and, accordingly, different ways of managing projects. Specifically we demonstrate that organizations that have performed well in new product development are ill-equipped to grasp the opportunities in fields where both technical solutions and uses are highly uncertain.

The Telematics Platform tried out at TelCar constitutes an organizational prototype, which broadly confirms the theoretical model of the project management of exploration projects that we have described in another context [41]. It illustrates the need to set-up a dedicated structure to manage the exploration of a "field of innovation" [39, 40]. But, at the same time, our research reveals some weaknesses. Firstly we explain the difficulty of involving the different departments concerned by the innovation (especially the sales networks, see [47]) or to take in projects initiated before the creation of the TP. Secondly, we show that the TP drift toward pure development, partly because of problems with a supplier and partly because of the reluctance of development projects to support uncertainty. Finally we propose five principles that form the outline of a project management model suited to the most complex innovation situations. They help define the nature of the desired objective (product and knowledge, gradual structuring of the innovation field) and discuss the nature of organizational settings suited to these situations.

More fundamentally, this research shows that the fundamental tension between exploitation and exploration, first analysed by J. March [51], applies to project management. We can therefore distinguish between two different views of projects that are complementary since new ideas are supposed, at least theoretically, to move smoothly from exploration to exploitation/development (see section 4.2 .2 on the problems raised by this transition).

In the exploitation perspective the role of the project is to organize the convergence to a predefined objective within a given set of constraints (time, budget, quality). Projects mainly exploit existing competences. The PMI or instrumental view of the project and the work from Clark \& Fujimoto falls within this approach.

In the second perspective, projects are a way of organizing the exploration of emerging innovation fields. But entering exploration entails a fundamental shift in project management methodology, with the risk of applying the exploitation framework to exploration. As shown by the present work and other recent research $[48,59]$ in 
exploration situations it is no more possible to define ex-ante the goal and the means to reach it. Projects thus became highly uncertain and reflexive probe and learn processes. In this perspective projects are first and foremost a way to explore and learn. They became a fundamental component of search processes [2]. This should lead us to revisit the fundamental nature of projects which are not only a set of management tools but more generally a way to construct the future and to break with past routines $[2,7,26]$. This research is a step in this direction.

\section{References}

[1] Abernathy W, Clark K. 1985. Innovation: mapping the winds of creative destruction. Research Policy 14(1): pp. 3-22

[2] Adler P, Obstfeld M. 2007. The role of affect in creative projects and exploratory search. Industrial and Corporate Change 16(1): pp. 19-50

[3] Adler P. 1989. Technology Strategy: A Guide to the Literatures. In R Burgelman, R Rosenbloom (Eds.), Research on Technological Innovation, Management and Policy, Vol. 4: pp. 25-151. JAI Press Inc.

[4] Atkinson R, Crawford L, Ward S. 2006. Fundamental uncertainties in projects and the scope of project management. International Journal of Project Management 24(8): pp. 687-698

[5] Balachandra R, Friar J. 1997. Factors of Success in R\&D projects and New Product Innovation: A Contextual Approach. IEEE Transactions on Engineering Management 44(3): pp. 276-287

[6] Ben Mahmmoud-Jouini S, Charue-Duboc F, Fourcade F. 2007. Multilevel Integration of Exploration Units: Beyond the Ambidextrous Organization., Academy of Management: Philadelphie, August.

[7] Boutinet JP. 2005. Anthropologie du projet (5ème ed.). PUF: Paris

[8] Brown SL, Eisenhardt KM. 1995. Product development: past research, present findings and future directions. The Academy of Management Review 20(2): pp. 343-378

[9] Brown SL, Eisenhardt KM. 1997. The art of continuous change: linking complexity theory and time-paced evolution in relentlessly shifting organizations. Administrative Science Quarterly 42(1): pp. 1-34

[10] Brown SL, Eisenhardt KM. 1998. Competing on the edge. Strategy as structured chaos. Harvard Business School Press: Boston, MA

[11] Burgelman R. 1983. A Process Model of Internal Corporate Venturing in the Diversified Major Firm. Administrative Science Quarterly 28(2): 223-244

[12] Burgelman R, Christensen C, Wheelwright S. 2004. Strategic Management of Technology and Innovation (4th ed.). Mc Graw Hill: Boston, MA

[13] Burns T, Stalker GM. 1994. The management of innovation (3rd ed.). Tavistock Publications

[14] Chapel V. 1997. La croissance par l'innovation: de la dynamique d'apprentissage à la révélation d'un modèle industriel. Le cas Tefal. Ecole Nationale Supérieure des Mines de Paris: Paris 
[15] Christensen C. 1997. The innovator's dilemma. Harvard Business School Press: Boston, MA.

[16] Christensen C, Roth E. 2002. OnStar: Not Your Father's General Motors (A). Harvard Business School Case 9-602-081

[17] Clark K, Chew B, Fujimoto T. 1987. Product development in the world auto industry. Brookings Papers on Economic Activity(3): pp. 729-771

[18] Clark K, Fujimoto T. 1991. Product development performance. Strategy, organization and management in the world auto industry. Harvard Business School Press: Boston, MA.

[19] Clark K, Wheelwright S. 1992. Organizing and leading heavyweight development teams. California Management Review 34(3): pp.9-28

[20] Cleland D, Ireland L. 2002. Project management: strategic design and implementation. (4th ed.). McGraw-Hill: Boston, MA

[21] Dougherty D, Hardy C. 1996. Sustained product innovation in large, mature organizations: overcoming innovation-to-organization problems. Strategic Management Journal 39(5): 1120-1153

[22] Duncan W. 1996. A Guide to the Project Management Body of Knowledge. PMI Publishing Division

[23] Eisenhardt KM. 1989. Building theories from case study research. Academy of Management Review 14(4): 532-550

[24] Eisenhardt KM, Tabrizi B. 1995. Accelerating adaptative processes: product innovation in the global computer industry. Administrative Science Quarterly 40: 84-110

[25] Ellison D, Clark K, Fujimoto T, Hyun Y. 1995. Product Development Performance in the Auto Industry: 1990s Update. Harvard Business School Working Paper 95-066.

[26] Emirbayer M, Mische A. 1998. What is Agency? American Journal of Sociology 103(4): pp. 963-1023

[27] Fujimoto T. 1999. The Evolution of a Manufacturing System at Toyota. Oxford University Press: Oxford

[28] Gastaldi L, Midler C. 2005. Exploration concourante et pilotage de la recherche. Une entreprise de spécialités chimiques. Revue Française de Gestion 31(155): pp. 173-189

[29] Gersick C. 1988. Time and transition in work teams: toward a new model of group development. Academy of Management Journal 31(1): 9-41

[30] Hamel G, Prahalad CK. 1994. Competing for the Future. Havard Business School Press: Boston, MA

[31] Hatchuel A, Weil B. 2003. A new approach to innovative design: an introduction to $\mathrm{C} / \mathrm{K}$ theory, International Conference on Engineering Design (ICED): Stockholm

[32] Holmberg G, LeMasson P, Segrestin B. 2003. How to manage the exploration of innovation fields? Toward a renewal of prototyping roles and uses, EURAM Conference: Milan

[33] Iansiti M. 1998. Technology Integration. Harvard Business School Press: Boston, MA

[34] Iansiti M, Clark K. 1994. Integration and dynamic capabilities: evidence from product development in automobiles and mainframe computers. Industrial and Corporate Change 3(3): pp. 507-605

[35] Imaï K, Nonaka I, Takeuchi H. 1985. Managing the new product developement process: how japanese companies learn and unlearn. In K Clark, R Hayes, C 
Lorenz (Eds.), The Uneasy alliance. Managing the productivity - technology dilemma.: pp. 337-376. Harvard Business School Press: Boston, MA.

[36] Kline S, Rosenberg N. 1986. An overview of innovation. In R Landau, N Rosenberg (Eds.), The Positive Sum Strategy: pp. 275-305. National Academy Press: Washington

[37] Krishnan V, Ulrich K. 2001. Product development decisions: a review of the literature. Management Science 47(1): 1-21

[38] Lawrence R, Lorsch JW. 1967. Differentiation and Integration in Complex Organizations. Administrative Science Quarterly 12(1): pp. 1-47

[39] Le Masson P. 2001. De la R\&D à la RID modélisation des fonctions de conception et nouvelles organisations de la R\&D. École Nationale Supérieure des Mines de Paris: Paris

[40] Le Masson P, Weil B, Hatchuel A. 2006. Les processus d'innovation. Hermès: Paris

[41] Lenfle S. 2001. Compétition par l'innovation et organisation de la conception dans les industries amont. Le cas d’Usinor. Université de Marne-la-Vallée: Champs-sur-Marne, France

[42] Lenfle S. 2004. Peut-on gérer l'innovation par projet? In G Garel, V Giard, C Midler (Eds.), Faire de la recherche en management de projet: pp. 35-54. Vuibert: Paris

[43] Lenfle S. 2005. L'innovation dans les services: les apports de la théorie de la conception. Economies et Sociétés, série "Economie et Gestion des Services" XXXIX, (11-12): pp. 2011-2036

[44] Lenfle S, Baldwin C. 2007. From Manufacturing to Design: An Essay on the Work of Kim B. Clark. Harvard Business School Working Paper(07 - 057)

[45] Lenfle S, Midler C. 2002. Stratégies d'innovation et organisation de la conception dans les entreprises amont. Enseignements d'une recherche chez Usinor. Revue Française de Gestion(140): 89-106

[46] Lenfle S, Midler C. 2003. Innovation in automotive telematic services: characteristics of the field and management principles. International Journal of Automotive Technology and Management 3(1/2): 144-159

[47] Lenfle S, Midler C. 2006. The launch of innovative services: lessons from automotive telematics. In $\mathrm{T}$ Buganza, R Verganti (Eds.), 13th International Product Development Conference, Vol. 2: pp. 805-821: Milano

[48] Loch C, DeMeyer A, Pich M. 2006. Managing the Unknown. A New Approach to Managing High Uncertainty and Risks in Projects. John Wiley \& Sons, Inc.: Hooboken, New Jersey

[49] Lynn LS, Morone JG, Paulson AS. 1996. Marketing and discontinuous innovation: the probe and learn process. California Management Review 38(3): 837

[50] Maidique M, Zirger B. 1990. A Model of New Product Development: an Empirical Test. Management Science 36(7): pp. 867-883

[51] March J. 1991. Exploration and exploitation in organizational learning. Organization Science 2(1): pp. 71-87

[52] Midler C. 1996. L'auto qui n'existait pas (2nd ed.). Dunod: Paris, France

[53] Miles M, Huberman M. 1994. Qualitative Data Analysis (2nd ed.). Sage Publications

[54] Mintzberg H, McHugh A. 1985. Strategy Formation in an Adhocracy. Administrative Science Quarterly 30(2): pp. 160-197

[55] Morris P. 1994. The Management of Projects. Thomas Telford: London 
[56] Morris P, Crawford L, Hodgson D, Shepperd M, Thomas J. 2006. Exploring the role of formal bodies of knowledge in defining a profession - The case of project management. International Journal of Project Management 24(8): pp. 710-721

[57] Nonaka I, Takeuchi H. 1986. The new new product development game. Harvard Business Review(64): pp. 137-146

[58] Shenhar A. 2001. One Size does not Fit All Projects: Exploring Classical Contingency Domains. Management Science 47(3): pp. 394-414

[59] Shenhar A, Dvir D. 2007. Reinventing Project Management. Harvard Business School Press: Boston, MA

[60] Shenhar A, Dvir D. 1996. Toward a typological theory of project management. Research Policy 25(4): pp. 607-632

[61] Shenhar A, Dvir D. 2004. How projects differ, and what to do about it. In P Morris, J Pinto (Eds.), The Wiley Guide to Managing Projects: pp. 1265-1286. Wiley: New-York

[62] Thomke S. 2003. Experimentation Matters. Harvard Business School Press: Boston, MA

[63] Tushman M, Anderson P. 1986. Technological discontinuities and organizational environments. Administrative Science Quarterly 31(3): pp. 439-465

[64] Tushman M, O'Reilly III C. 1996. Ambidextrous Organizations: Managing Evolutionary and Revolutionary Change. California Management Review 38(4): pp. 8-30

[65] Van de Ven A. 1986. Central problems in the management of innovation. Management Science 32(5): 590-607

[66] Van de Ven A, Polley D, Garud R, Venkataraman S. 1999. The innovation journey. Oxford University Press: New-York

[67] Wheelwright S, Clark K. 1992. Revolutionizing product development. Quantum leaps in speed, efficiency and quality. The Free Press: New-York

[68] Winer R. 2001. A framework for CRM. California Management Review 43(4)

[69] Yin R. 2003. Case Study Research. Desing and Methods. (3rd ed.). Sage Publications: Thousand Oaks, CA 